\title{
Evaluation of Collapse Sensitivity of Loess Soils and Its Effect on the Distribution Pattern of Pseudokarst Sinkholes at the Regional Scale (Case Study: Golestan Province, Northeastern Iran)
}

Seddighe Zalaghaie

Bu Ali Sina University

Mojtaba Heidari ( $\square$ heidarim_enggeoll@yahoo.com )

Basu: Bu Ali Sina University https://orcid.org/0000-0001-7424-3644

Mohammad Reza Nikudel

Tarbiat Modares University

\section{Research Article}

Keywords: Pseudokarst sinkholes, Collapse sensitivity, Collapse rate, Coefficient of collapse, Golestan Province Posted Date: September 24th, 2021

DOI: https://doi.org/10.21203/rs.3.rs-826494/v1

License: (c) (i) This work is licensed under a Creative Commons Attribution 4.0 International License. Read Full License 


\section{Abstract}

The spread of loess soils in Golestan Province in northeastern Iran has caused considerable environmental issues. To evaluate the effect of loess collapse on the spatial distribution of pseudokarst sinkholes in this province, we have prepared undisturbed samples from 31 locations and characterized their physical and mechanical properties. Moreover, the collapse sensitivity in different parts of the study area has been determined by odometer tests under different pressures and calculation of three parameters, namely, the collapse coefficient (Ic), the time required for 90\% settlement due to soil collapse (T90\%), and initial collapse stress. Additionally, by conducting field surveying, using aerial photographs, satellite images, and drone flight, the coordinates of sinkholes were identified, and a map of their geographical distribution was prepared. The overlap of the sinkholes distribution map and the coefficient of collapse changes map showed that although the amount of Ic of sandy loess soils (Zone III) is higher than that of silty loess soils (Zone II), the extent of destructive phenomena such as sinkholes is much greater in Zone II than in Zone III. The overlap of the map of sinkholes distribution with the map of changes in collapse sensitivity (Is) of loess soils showed that the density of sinkholes in Zone II (which has higher collapse sensitivity) is higher than Zone III. In Zone II, due to severe collapse sensitivity, the highest concentration of sinkholes is observed in a unit area, more than 0.18 per square kilometer. With a relatively severe to severe collapse sensitivity in Zone III, this concentration is 0.021 per square kilometer. In Zone I (clayey loess), with slight-moderate collapse sensitivity, this destructive phenomenon is observed in the form of side instability since the study area is located in highlands. Furthermore, in this area, the sinkholes (0.004 per square kilometer) have the least concentration.

\section{Introduction}

Loess soils are pale yellow problematic aeolian deposits with the silt size range. These deposits are rich in quartz and carbonate cement and are found in arid and semi-arid regions. High porosity, open structure, poor cementation, and unsaturation are the main features of these soils (Smalley et al. 2011). Collapsing due to increased moisture is their most important feature (Delage et al. 2005; Kim and Kang 2013; Liang et al. 2018; Zhang et al. 2018).

The widespread expansion of loess soils (17\%) in Golestan Province in northeastern Iran (Frechen et al. 2009) causes geomorphological features such as gully, pseudokarst sinkholes, ground cracking, slide of water supply channel walls, sudden and asymmetric settlements, cracking of house walls, destruction of pastures, soil erosion, and destruction of roads and bridges. Figure 1a shows the dimensions of pseudokarst sinkholes in Cheshme li village, and Fig. 1b presents the bending of the gas transmission pipe of houses. Also, Fig. 1c illustrates the asymmetric settlement of the building in Feraghi city in the northeast of Golestan Province, and Fig. 1d shows the loess sinkholes developed along the Kalaleh-Maraveh Tappe road.

Various erosional and geomorphological forms, including pseudokarst sinkholes, gully, and hillside instabilities, have been reported in the loess soils of the province. Despite numerous studies addressing hillside instability (Arabameri et al. 2017; Arabameri et al. 2019; Ghorbanzadeh et al. 2021; Mohammady et al. 2012; Pourghasemi et al. 2019; Zare et al. 2013) and gully erosion (Amiri and Pourghasemi 2020; Amiri et al. 2019; Arabameri et al. 2019; Arabameri et al. 2018; Ghezelsofloo et al. 2018; Hosseinalizadeh et al. 2020; Pourghasemi et al. 2017; Soufi 2002), considerably fewer researches have been conducted to analyze the factors affecting the pseudokarst sinkholes in Golestan Province (Hosseinalizadeh et al. 2019; Hosseinalizadeh et al. 2018; Kariminejad et al. 2020; Kariminejad et al. 2019). 
Pseudokarst sinkholes were first defined in China as piping (Richthofen 1877) features. This phenomenon also has been called sub-surface erosion (Fuller 1922), ground collapse (Galarowski 1976), erosional sinkhole (Buckham and Cockfield 1950), erosional pothole (Kingsbury 1952), pseudokarst sinkholes (Kriger et al. 1983), and loess caves (Penga et al. 2017). Among these names, the present article applies the term pseudokarst sinkholes.

A review of research and field studies showed that the spatial distribution of pseudokarst sinkholes changes under the influence of a combination of natural conditions, including topography, annual rainfall, climatic conditions, and artificial factors such as land use (Hosseinalizadeh et al. 2018; Kariminejad et al. 2019; Pandey et al. 2019). Three categories of geological, geotechnical, and environmental factors affect the collapse potential of loess soils. Identifying these factors and their effects in creating new pseudokarst sinkholes in different areas of Golestan Province is of substantial importance for sustainable development planning. This study only deals with the geotechnical factors of loess soils in Golestan Province's effect on the distribution of sinkholes.

In the previous studies regarding the effect of loess soil behaviour on the occurrence of destructive phenomena such as pseudokarst sinkholes, the coefficient of collapse (Ic) of loess soils has been noted to be the most critical parameter in addressing the susceptibility of this phenomenon (Guan 1983; Hou et al. 2019; Jennings and Knight 1975; Reznik 2007; Salehi et al. 2015; Xie et al. 2018). Ic is a function of the distribution of soil particle size, porosity, degree of saturation, percentage of initial moisture, pore size between soil particles, soil liquid limit, and percentage of calcium carbonate. However, some new studies have shown that despite having a higher lc, the risk of destructive phenomena may be lower in some areas (Lutengger 2012; Zhang et al. 2018). The concept of collapse sensitivity $\left(I_{S}\right)$ is defined based on the intensity and rate of collapse (Zhang et al. 2018). In the present study, by conducting laboratory experiments on loess soils of Golestan Province, the values of Ic, collapse rate of soil (T90\%), and initial collapse stress were calculated, and the degree of collapse sensitivity was determined accordingly.

Moreover, the location of pseudokarst sinkholes was determined by conducting field surveys and using aerial photographs, satellite images, and drone flight. It is noteworthy that spatial distribution of sinkholes is preferentially restricted to arid and semi-arid regions with less than $400 \mathrm{~mm}$ annual precipitation, gentle hillslopes (less than $20^{\circ}$ ), and altitudes below $400 \mathrm{~m}$ above sea level. Although extrinsic environmental factors are the subject of a forthcoming article, we would tentatively emphasize two intrinsic parameters, including collapse coefficient and collapse s sensitivity, since all collapsed areas are restricted to loess soils. Overall, the main objective of this study was to study the relationship between the collapse sensitivity of the soils of Golestan Province and the spatial distribution of pseudokarst sinkholes.

\section{Geographical And Geological Location Of The Study Area}

The loess plateau of northeastern Iran includes loess deposits that extend from south to north of Golestan Province between longitudes $54^{\circ} 00^{\prime} \mathrm{E}$ to $56^{\circ} 00^{\prime} \mathrm{E}$ and latitudes $36^{\circ} 15^{\prime} \mathrm{N}$ to $36^{\circ} 30^{\prime} \mathrm{N}$ (Fig. 2).

These soils are considered to be the southern part of the Eurasian loess belt (Keshavarzi 2014). Golestan Province is located in the southeast of the Caspian Sea and is part of the structural Zone of Kopet Dagh (Karimi et al. 2009). The thickness of loess soils in Golestan Province decreases from northeast to southwest of the province (30 to 150 $\mathrm{m}$ ) (Frechen et al. 2009). Based on the geotechnical and sedimentological characteristics of the loess soils of the study area, from south to north, these features are divided into clayey (Zone I), silty (Zone II), and sandy loess soils (Zone III), respectively (Fig. 3 ). 
The study area is located in Zone I, south of the province. The local height difference in this morphological unit is usually more than $500 \mathrm{~m}$, and the area is $501 \mathrm{~km}^{2}$. The steep slope and high altitude are the main morphological features of this region. According to the arid/humid climate classification De Martonne (De Martonne 1920), Zone I would be classified as moist to semi-moist. The annual rainfall in the region is between 500 and $750 \mathrm{~mm}$ (Table 1). Zone I loess soils have a fragile structure due to high percentage of clay (Rezaiy et al. 2011). The average percentage of clay in this area reaches 30\% (Okhravi and Amini, 2001). Since the soils of this region are transported from a considerable distance from their origin (Turkmenistan desert), they are finer than the loess soils of other areas. Due to wind direction, soil particle size decreases from north to south, northwest to southeast, and west to east. The cohesion of these soils is greater than that of Zones II and III.

The area of Zone II in the middle part of Golestan Province is $3258 \mathrm{~km}^{2}$. The local height difference in this Zone is between 50 and $500 \mathrm{~m}$. This Zone is morphologically composed of hills where, particularly in the northeastern region of Gonbad Kavous, the gradient of the slopes is in the range of 8 to $25 \%$. Most of the loess soils in this Zone are composed of silt particles and are considered silty loess. Based on the De-Marttone classification, Zone II is in the semi-arid category, and the average rainfall is 250 to $500 \mathrm{~mm}$. However, in the Gonbad Kavous region, the annual rainfall varies between 500 to $750 \mathrm{~mm}$ (Table 1).

The area of Zone III is more than $864 \mathrm{~km}^{2}$. In this Zone, the soils are coarser and fall in the category of sandy loess soils. The local height difference is less than $50 \mathrm{~m}$, and most of the area is relatively flat with a less than $8 \%$ gradient. In the south, the gradient increases because of the highland topography, while the general gradient decreases in the north. Annual rainfall in this Zone is between 50 to $250 \mathrm{~mm}$ and would fall in the dry climate category (Table 1). The percentage of $\mathrm{CaCO}_{3}$ in this Zone is the highest compared to other zones (maximum $41.4 \%)$.

\section{Materials And Methods \\ 3.1. Field surveying}

The location of pseudokarst sinkholes was recorded by field surveys and using Global Positioning System (GIS). The DJI Phantom-4 quadcopter with a digital camera was used to capture the sinkholes by placing the ground restraint points and preparing all the required necessities. By interpreting images of unmanned aerial vehicles (UAV) with a resolution of $50 \mathrm{~cm}$ and using satellite images and aerial photographs, the position of more than 697 pseudokarst sinkholes was recorded. The maximum flight duration was $30 \mathrm{~min}$. The flight path was determined using Pix4 Capture software. The drone automatically traveled the defined air routes and covered the entire area. After the flight operation, the data were processed, and the location of pseudokarst sinkholes was determined accordingly.

\subsection{Laboratory tests}

To evaluate the physical and mechanical parameters controlling the distribution of pseudokarst sinkholes, we prepared undisturbed block samples from 31 points in Zones I, II, and III. All samples were placed in $20 \times 20 \times 20$ $\mathrm{cm}$ boxes after waxing and were transferred to the engineering geology laboratory. Some of the physical, mechanical, and chemical properties of the sample were carried out based on ASTM standards (Table 1).

Also, an odometer test was performed based on (ASTMD5333-03 2003) standard. 
Seven samples with a diameter of $75 \mathrm{~mm}$ and a height of $20 \mathrm{~mm}$ were obtained and prepared from each sampling site to determine the Ic, collapse rate, and initial stress required for collapse. These samples were subjected to pressures of $25,50,100,200,400,800$, and $1600 \mathrm{Kpa}$. In the standard method, the coefficient of the collapse of the soils is to be determined at a pressure of $200 \mathrm{Kpa}$. However, in the present study, the coefficient of the collapse of the soils was determined under different pressures. Loading steps were 25, 50, 100, 200, 400, and $800 \mathrm{Kpa}$, respectively. The amount of deformation at each stage of loading was read at intervals of $0.1,0.25,0.5,1,2,4,6,9$, $12,16,20,25,30,45$, and $60 \mathrm{~min}$. Then it was continued at intervals of 30 min until reaching a stable state (deformation value less than $0.01 \mathrm{~mm}$ per hour).

\section{Results And Discussion}

\subsection{Changes in collapse intensity and initial resistance of soils against the collapse}

Table 1 shows some of the physical, mechanical, and chemical properties of loess soils at sampling points. Generally, it can be claimed that the coefficient of the collapse of the loess soils decreases from the north of Golestan (sandy loess) to the south (clayey loess). Furthermore, the values of liquid limit, percentage of fine clay particles, percentage of moisture, and the degree of initial saturation of soils increase from north of the province southwards. However, the percentage of $\mathrm{CaCO}_{3}$ decreases from north to south of the province. These findings are consistent with the results of previous research (Rezaiy et al. 2011; Salehi et al. 2015).

The collapse intensity of loess soils was determined based on calculated lc value using Eq. (1) (ASTM D5333 2003):

$$
I_{C}=\frac{\Delta h}{h_{0}}
$$

Where $\Delta \mathrm{h}$ is the vertical deformation of the soil sample after saturation under constant stress, and $\mathrm{h}_{0}$ is the initial height of the soil sample. Variations in the Ic values for samples from these three zones are shown in Fig. 4.

As evident in Fig. 4c, for soil samples from Zone III, the Ic values are generally higher than that of other zones. In the soil samples from Hootan, Alagol and Tange Ali, the highest value of Ic was observed at a pressure of $200 \mathrm{Kpa}$, and it would drop at higher vertical stresses. The oedometer test results showed that in these samples, under a stress of $200 \mathrm{kPa}$, the stability of the soil would prevent soil deformation mainly due to the cementation and the suction force between the particles in the natural moisture. However, at the same stress of $200 \mathrm{Kpa}$, immediately after saturation of the soil sample, the suction force and cementation between the soil particles would vanish, and the soil sample would display the maximum deformation, and thus, the maximum value of Ic would be observed. At vertical pressures greater than $200 \mathrm{kPa}$, cementation due to calcium carbonate between soil particles would disappear even at natural moisture. As a result, the soil structure and the connections between soil particles would easily break after saturation; subsequently, the soil sample could easily be compressed, and the porosity ratio of the soil sample would reduce significantly. Therefore, at pressures of $400 \mathrm{kPa}$ and above, the collapse due to soil saturation would decrease. As a result, lc would reduce invertical stress rates up to $1600 \mathrm{kPa}$. 
The Ic deviations corresponding to different vertical pressures are presented in Fig. 4.b for the soil samples of Zone II. As it is evident, in Zone II, in the soils of Cheshmehli and Feraghi, Ic values would increase from 25 to $800 \mathrm{kPa}$ vertical stresses and from 25 to $400 \mathrm{kPa}$ in Gonbad and Kalaleh soils (Fig. 4.b), and then, it would drop in greater pressures. In general, in Zone II soils, the soil structure is more stable than in Zone III. In Cheshmehli and Feraghi soils, the porosity ratio of soil samples would slightly reduce in natural moisture under stresses up to $800 \mathrm{kPa}$. However, immediately after saturation, the values would change significantly. Therefore, the highest Ic in this region was measured at a stress of $800 \mathrm{kPa}$. At pressures above $800 \mathrm{kPa}$, the soil void ratio would decrease significantly before the samples become saturated, and therefore the lc value decreases at a stress of $1600 \mathrm{kPa}$.

The clayey loess soil samples collected from Zone I were not collapsible in some areas and had a lower Ic than Zones II and III. These soils usually showed the highest value of Ic at $200 \mathrm{kPa}$ (Fig. 4.c). In Zone I, soil samples had more natural moisture, and the initial degree of soil saturation was high; as a result, the amount of suction force between soil particles was insignificant, and also the percentage of calcium carbonate between soil particles was low. Therefore, the amount of cementation of soil samples was negligible, and only in the Baraftan area, the amount of $\mathrm{CaCO}_{3}$ would reach more than $30 \%$; this was mainly in the form of calcite nodules and, therefore, would not play the role of cement between particles (Salehi et al., 2015). Generally, it can be claimed that the collapse intensity of loess soil would decrease from the north to the south of Golestan Province. This finding is consistent with the results of other researchers.

This research evaluated the soil susceptibility to collapse in Golestan Province by determining the initial collapse stress $\sigma_{i}$ for loess soil samples. Considering the lc of $1.5 \%$ as the boundary between collapsible and noncollapsible soils, the amount of vertical stress corresponding to the coefficient of the collapse of $1.5 \%$ was defined as the initial collapse stress in Fig. 4. The values of $\sigma_{i}$ would vary in different zones (Zone I: in the range of 44 to 67 $\mathrm{kPa}$, Zone II: from 56.5 to $100 \mathrm{kPa}$, and Zone III: from 23 to $45 \mathrm{kPa}$ ). Sandy loess soils in Zone III had the lowest value of $\sigma_{\mathrm{i}}$. For example, for soil sample $\mathrm{H} 1$, obtained from the Hootan region, the value of $\sigma_{\mathrm{i}}$ was $23 \mathrm{Kpa}$ (Fig. 4-c). However, for the $\mathrm{CH} 3$ soil sample, this value was about $100 \mathrm{Kpa}$. Therefore, it can be claimed that more stress would be needed to start the destruction of soil in Zone II, having higher values of $\sigma_{i}$. Consequently, the maximum IC in Zone II and III soils were measured at stress levels of $800 \mathrm{Kpa}$ and $200 \mathrm{Kpa}$ respectively, as it is evident in Fig. 4.

\subsection{Collapse rate of soil samples}

The collapse rate is defined as the time required for the complete collapse of loess soils. This parameter is significant in evaluating the risks of a destructive phenomenon (Cui 2010; Guan 1983; Zhang et al. 2017). In simple words, as the collapse rate increases, the risk of danger would grow.

To determine the collapse rate of soils in the study area, we read the amount of deformation at each loading stage after saturation of the sample at specified intervals. The deformation was continuously read until a deformation value threshold of less than $0.01 \mathrm{~mm}$ per hour. The required deformation rates less than $0.01 \mathrm{~mm}$ per hour are called stability time. Since the time required for $10 \%$ of the final settlement of collapsible soils is considerably longer compared to the time required for $90 \%$ settlement of these soils, it has been suggested that for an accurate comparison between the collapse rates of these soils, the time required for $90 \%$ of their settlement (T90\%) should be used (Zhang et al. 2018) instead of the stability time; therefore, removing the final 10\% of the settlement, which requires a considerable amount of time, could help with a more effective and accurate comparison of the collapse 
speeds of different soils. The experimental results supported (were in favor of) this suggestion. Table (2) shows the stability time and $\mathrm{T} 90 \%$ of soil samples of the triple zones.

For instance, for the soil samples of the Hootan $(\mathrm{H} 1)$ area, the time required for complete settlement $(\mathrm{T})$ was 247 min, which is equivalent to 1.83 times the time required for complete settlement of Cheshmehli sample (CH1), i.e., $135 \mathrm{~min}$. However, the time required for the settlement of $90 \%$ (T90\%) of the soil samples in the Hootan area $(\mathrm{H} 1)$ was $14.2 \mathrm{~min}$, equal to slightly more than four times T90\% of the soil samples of Cheshmehli (CH1), i.e., $3.5 \mathrm{~min}$.

As can be seen (table2), the lowest and highest $\mathrm{T} 90 \%$ values were obtained for the $\mathrm{CH} 1$ sample (Cheshmehli) in Zone II (3.5 min) and the SAD1 sample (Saad Abad) in Zone I (122.7 min). The results of the odometer test showed that the T90\% for Zone III would vary between 14.2 and $55.4 \mathrm{~min}$. The range was between 3.5 to $76.3 \mathrm{~min}$ for Zone II and between 66.33 and $122.7 \mathrm{~min}$ for Zone I. With the exception of the central parts of Zone II, namely GonbadKalaleh and Aghabad, which experience more rainfall in these areas, the time required for the settlement of $90 \%$ of the soils of Zone III were longer than that of the soil samples of Zone II. Since the soil collapse susceptibility is higher in Zone III compared to Zone II, more time would be needed to reach the complete settlement due to collapse. However, Zone II loess soils have a stronger structure, and soil saturation has less effect on the rate of sudden collapse and degradation of soil structure, and as a result, the samples display a lower Ic value. Since the value of Ic in the soils of this Zone is less than the collapse coefficient of the soils of Zone III, the time required to reach $90 \%$ of the settlement due to collapse is less; and more precisely, the collapse rate in Zone II is higher than Zone III. The collapsibility deformation rate of loess is essential when assessing the potential damage caused by collapse since a rapid collapse commonly causes cracking, tilting, and the collapse of construction components (Guan 1983).

This situation in Zone I is not affected by vertical stress changes because of the presence of clay minerals despite having a lower collapse coefficient. Despite having lower settlement due to lower Ic values, Zone I soils require longer $90 \%$ settlement time because of the cohesion between soil particles due to the presence of clay matrix.

\subsection{Determining the collapse sensitivity of the soil}

The criterion of soil collapse sensitivity is presented in Table 3, considering the two parameters of collapse intensity (IC) and collapse rate (T90\%) defined by Zhang et al. (2018).

Using the results of laboratory tests, we divided the soils into four categories based on the value of the Ic:

$\mathrm{Ic}<1.5,1.5<\mathrm{Ic} \leq 33<\mathrm{Ic} \leq 7, \mathrm{Ic}>7$.

Also, soils were divided into four categories based on T90\%:

$\mathrm{T} 90 \%<5 \mathrm{~min}, 5<\mathrm{T} 90 \% \leq 15 \mathrm{~min}, 15 \mathrm{~min}<\mathrm{T} 90 \% \leq 60 \mathrm{~min}, \mathrm{~T} 90 \%>60 \mathrm{~min}$.

Based on two factors, intensity (IC) and time of collapse (T90\%), soils were divided into four categories of: low, medium, medium to severe, and severe collapse sensitivity (Is). To evaluate the accuracy and efficiency of this classification, we calculated Ic and T90\% values for 31 points in Golestan Province, and the collapse sensitivity status of loess soils in three Zones I, II, and III was determined (Table 4).

As can be seen, in Zone I, where clayey loess soils are spread, the soil sensitivity was relatively low. In Zone II, where silty loess soils are abundant, the soil sensitivity was severe and, in some places, relatively severe. However, 
in Zone III, the collapse sensitivity of soil was often relatively severe and rarely severe, considering the higher Ic values of its soil compared to that of Zone II.

\subsection{Investigating the relationship between the spatial distribution of sinkholes and Ic and collapse sensitivity of the loess soils}

To investigate the relationship between the formation of pseudokarst sinkholes and changes in collapse coefficient (Ic) and collapse sensitivity (Is), we plotted the position of pseudokarst sinkholes on the scattering map of Golestan Province. Nineteen sinkholes in Zone I with an area of 501 km², 580 sinkholes in Zone II with 3258 km², and 98 sinkholes in Zone III with 864 km2 were identified recorded (Fig. 5). In this figure, the density of the sinkholes per unit area in each Zone is denoted by colored symbols.

More than $83 \%$ of pseudokarst sinkholes were located in Zone II, more than $14 \%$ in Zone III, and less than $3 \%$ in Zone I. By preparing a map of soil collapse potential risk based on changes in collapse coefficient of loess soils in Golestan Province, the relationship between deviations in collapse coefficient and spatial distribution of sinkholes based on Jennings and Knight (1975) classification and its overlap with the sinkholes' distribution map (Fig. 6) was investigated.

As can be seen, although Zone III is very intense in terms of collapse coefficient, the concentration of sinkholes in this Zone (161 sinkholes equivalent to about 23\%) is less than Zone II (517 sinkholes equivalent to more than $71.4 \%)$. Zone II is in a severely problematic category. Therefore, it can be claimed that having a higher Ic in Zone III does not necessarily mean a higher risk of pseudokarst sinkholes in this Zone.

By preparing a map of collapse sensitivity of the soil and its overlap with the sinkholes' distribution map (Fig. 7), the relationship between changes in the degree of collapse sensitivity and sinkholes' distribution was investigated.

The regional developing regularities of loess sinkholes showed that more than $84.6 \%$ of the sinkholes were distributed in the region with a high degree of collapse sensitivity, more than $12.6 \%$ in the region with a relatively severe collapse sensitivity, $2 \%$ in the region with a moderate collapse sensitivity, and $0.7 \%$ in the region with a low collapse sensitivity. More than $91.5 \%$ of sinkholes in Zone II have severe collapse sensitivity, and the remaining $8.5 \%$ are in the area with relatively high collapse sensitivity. However, in Zone III, more than $60 \%$ of the sinkholes are located in the area with severe collapse sensitivity, and less than $40 \%$ of the rest are located in the area with relatively severe collapse sensitivity. In Zone I, more than $73 \%$ of the sinkholes are located in the area with moderate collapse sensitivity, and the rest are in the area with low collapse sensitivity. Based on these results, it can be suggested that the application of collapse sensitivity index (Is) to investigate the risk of pseudokarst sinkholes in Golestan Province would provide a more appropriate assessment than that of Ic.

The developmental regionalization of loess sinkholes and the loess sensitivity collapse and collapse speed are closely related. The loess sinkholes are often developed in Zone II, where the collapse sensitivity is intense. Some essential characteristics of loess, such as greater silt amounts in the composition, high collapse speed, greater porosity, the disintegrability of silty loess, and overall, higher average soil $\mathrm{CaCO}_{3}$ content, attribute to higher sinkhole formation rate in this Zone, specifically in the northeastern part of Golestan Province. Regarding the regional distribution of sinkholes, it can be seen that in Zone III, the formation of the loess sinkholes is scarcer due to considerably higher proportions of sand (sandy loess). Likewise, the loess sinkholes are less developed in the south of Golestan province with clay loess, having a strong erosion resistance, low collapsibility, and weak disintegrability and permeability. 


\section{Conclusions}

In this research, collapse intensity, rate, and sensitivity of loess soils of Golestan Province were determined by performing laboratory tests. Afterward, maps of changes in coefficients of collapse (Ic), maps of changes in collapse sensitivity (Is), and maps of scattering of loess soils in the study area were prepared. The location of pseudokarst sinkholes was recorded, and spatial distribution maps of the sinkholes were prepared using satellite images, aerial photographs, drone flight, and field navigation. We also evaluated the efficiency of applying Is and Ic in explaining the spatial distribution and density of pseudokarst sinkholes due to the collapse of loess soil at regional scale in Golestan Province. Overall, the results can be outlined as follows:

-The spatial distribution and density of pseudokarst sinkholes are directly related to the collapse sensitivity of loess soils in the province. More than $84 \%$ of the sinkholes were distributed in the area with severe collapse sensitivity, $12.6 \%$ in the area with relatively severe collapse sensitivity, $2 \%$ in the area with moderate collapse sensitivity, and $0.7 \%$ in an area with low collapse sensitivity. The highest density of sinkholes per unit area occurred in Zone II, i.e., in the area with high collapse sensitivity. In Zones III and I, which have a relatively higher and lower collapse sensitivity than Zone II, the density of sinkholes per unit area was less.

-The results show that higher Ic values in Zone III do not necessarily comply with a higher risk of pseudokarst sinkholes there. In Zone II, the higher collapse rate and, as a result, the severe collapse sensitivity increases the potential for pseudokarst sinkholes compared to Zone III, which has a greater Ic value. Combining the two parameters of Ic and the time required for $90 \%$ settlement due to soil collapse (T90\%) can be a reasonable basis for judging the risk of pseudokarst sinkholes in the region.

-The initial collapse stress $\left(\sigma_{\mathrm{i}}\right)$ in highly sensitive soils (Zone II) is higher than Zones III and I. In other words, the initial collapse stress is directly related to the degree of collapse sensitivity of loess soils in the region. Since few soil samples were tested and analyzed in this research, applying the initial collapse stress $\left(\sigma_{\mathrm{i}}\right)$ data for a more accurate classification of the collapse sensitivity of loess soils would not be possible.

- Considering the small amount of available data in this research, the findings of this study have only local value and cannot be extended to other collapsible soils.

\section{Declarations}

\section{Acknowledgments}

This short communication would not have been possible without the effort of numerous authors whose publications were cited in this article. The authors appreciate the Bu-Ali Sina University research council for its financial support.

\section{References}

1. Amiri, M., Pourghasemi, H.R (2020) Mapping and preparing a susceptibility map of gully erosion using the MARS Model. In: Shit, P., Pourghasemi, H. (Eds.), Gully Erosion Studies from India and Surrounding Regions. Springer, Cham, pp. 405-413, https://doi.org/1007/978-3-030-23243-6_27. 
2. Amiri, M., Pourghasemi, H.R., Ghanbarian, G.A., Afzali, S.F (2019) Assessment of the importance of gully erosion effective factors using Boruta algorithm and its spatial modeling and mapping using three machine learning algorithms. Geoderma, 340, 55-69, https://doi.org/1016/J.GEODERMA.2018.12.042.

3. Arabameri, A., Pradhan, B., Pourghasemi, H. R., Rezaei, K., \& Kerle, N (2018) Spatial Modelling of Gully Erosion Using GIS and R Programing: A Comparison among Three Data Mining Algorithms. Applied Sciences, 8(8), 1369, doi: 10.3390/app8081369.

4. Arabameri, A., Pradhan, B., \& Rezaei, K (2019) Spatial prediction of gully erosion using ALOS PALSAR data and ensemble bivariate and data mining models. Geosciences Journal, doi: 10.1007/s12303-018-0067-3.

5. Arabameri, A., Pradhan, B., Rezaei, K., Sohrabi, M., \& Kalantari, Z (2019) GIS-based landslide susceptibility mapping using numerical risk factor bivariate model and its ensemble with linear multivariate regression and boosted regression tree algorithms. Journal of Mountain Science, 16(3), 595-618, doi: 10.1007/s11629-0185168-y.

6. Arabameri, A.R., Pourghasemi, H.R., Yamani, M (2017) Applying different scenarios for landslide spatial modeling using computational intelligence methods. Environ. Earth Sci, 76, 832. [CrossRef].

7. ASTM International (2003) ASTM D5333-03. Standard test method for measurement of collapse potential of soils. ASTM International, West Conshohocken, PA.

8. Buckham, A.F., Cockfield, W.E 1950 Gullies formed by sinking of the ground. Am. J. Sci. 248, 137-141, https://doi.org/10.2475/ajs.248.2.137.

9. Cui, YE (2010) Discussion on the issue of sensitivity of loess collapse. Coal Eng, 8, 76-78 (in Chinese), https://doi.org/10.3969/j.issn.1671-0959.2010.08.030.

10. De Martonne Em (1920) Géographie physique (Physical geography), (Third edn) Armand Colin. Paris, France.

11. Delage, P., Cui1, Y.J., Antoine, P (2005) Geotechnical problems related with loess deposits in Northern France. Proceedings of International Conference on Problematic Soils, Eastern Mediterranean University, Famagusta, N. Cyprus, 25-27.

12. Frechen, M., Kehl, M., Rolf, C., Sarvati, R., \& Skowronek, A (2009) Loess chronology of the Caspian Lowland in Northern Iran. Quaternary International, 198(1-2), 220-233, doi:10.1016/j.quaint.2008.12.012.

13. Fuller, M.L 1922 some unusual erosion features in the Loess of China. Geogr. Rev. 12, 570-584. https://doi.org/10.2307/208591.

14. Galarowski, T 1976 New observations of the present-day suffosion (piping) processes in the Bereźnica catchment basin in The Bieszczady Mountains (The East Carpathians). Stud. Geomorphol. CarpathoBalcanica 10, 115-122.

15. Ghezelsofloo, A.A., Maghrebi, M., Daroughe, F (2018) Identification of expansion rate in active gullies using remote sensing. J. Water Sustain. Develop, 5 (1), 67-72 (in Persian).

16. Ghorbanzadeh O, Meena SR, Abadi HSS, Piralilou ST, Zhiyong L, Blaschke T 2021 Landslide mapping using two main deep-learning convolution neural network (CNN) Streams combined by the Dempster-Shafer (DS) model. IEEE J Sel Top Appl Earth Obs Remote Sens. 14:452-463.

17. Guan, WZ (1983) Preliminary study on factors affecting the sensitivity of self-weight collapsible loess and its discriminant index. Site Investig Sci Technol, 4, 32-35 (in Chinese).

18. Hosseinalizadeh, M., Alinejad, M., Behbahani, A.M., Khormali, F., Kariminejad, N., Pourghasemi, H.R (2020) A Review on the Gully Erosion and Land Degradation in Iran. In Gully Erosion Studies from India and Surrounding Regions. Springer, Cham, 393-403. 
19. Hosseinalizadeh, M., Kariminejad, N., Alinejad, M (2018a) An application of different summary statistics for modelling piping collapses and gully headcuts to evaluate their geomorphological interactions in Golestan Province, Iran. Catena, 171, 613-621, https://doi.org/10.1016/j.catena 201808.005

20. Hosseinalizadeh, M., Kariminejad, N., Chen, W., Pourghasemi, H.R., Alinejad, M., Behbahani, A.M., Tiefenbacher, J.P (2019) Spatial modelling of gully headcuts using UAV data and four best-first decision classifier ensembles (BFTree, Bag-BFTree, RSBFTree, and RF-BFTree). Geomorphology, 329, 184-193, https: //doi.org/10.1016/j. geomorph.2019.01.006.

21. Hou, X., Vanapalli, S. K., \& Li, T (2019) Wetting-induced collapse behavior associated with infiltration: A case study. Engineering Geology, 258,105146, https:// doi:10.1016/j.enggeo.2019.105146.

22. Jennings, J.E., Knight, K (1975) A guide to construction on or with materials exhibiting additional settlement due to collapse of grain structure. Proceedings of the 6th African conference on soil mechanics and foundation engineering, 99-105.

23. Karimi, A., Khademi, H., Kehl, M., \& Jalalian, A (2009) Distribution, lithology and provenance of peridesert loess deposits in northeastern Iran. Geoderma, 148(3-4), 241-250, doi:10.1016/j.geoderma.2008.10.008.

24. Kariminejad, N., Hosseinalizadeh, M., Pourghasemi, H. R., Bernatek-Jakiel, A., Campetella, G., \& Ownegh, M (2019) Evaluation of factors affecting gully headcut location using summary statistics and the maximum entropy model: Golestan Province, NE Iran. Science of the Total

Environment. doi:10.1016/j.scitotenv.2019.04.306

25. Kariminejad, N., Rossi, M., Hosseinalizadeh, M., Pourghasemi, H. R., \& Santosh, M (2020) Gully head modelling in Iranian Loess Plateau under different scenarios. CATENA, 194, 104769. doi:10.1016/j.catena.2020.104769

26. Keshavarzi, B (2014) A possible link between mineralogy of loess deposits and high incidence rate of esophageal cancer in Golestan Province of Iran. Iranian Journal of Science \& Technology, 38 (A3), 281-287.

27. Kim, D., Kang, SS (2013) Engineering properties of compacted Loesses as construction materials. KSCE J Civ Eng, 17(2), 335-341, https://doi. org/10.1007/s12205-013-0872-1.

28. Kingsbury, J.W 1952 Pothole erosion on the western part of Molokai Island. Territory of Hawaii. J. Soil Water Conserv. 7, 197-198.

29. Kriger, N.I.; Botnikov, V.I.; Lavrusevich, S.A.; Mironyuk, S.G.; Petrov, A.G (1983) Pseudokarst in loess rocks. Geomorphology 3, 79-84 (in Russian).

30. Liang, H., Xue, Y., Li, Z., Wang, S., Wu, X., Gao, G., Fu, B (2018) Soil moisture decline following the plantation of Robinia pseudoacacia forests: Evidence from the Loess Plateau. Forest Ecology and Management, 412, 6269, doi:10.1016/j.foreco.2018.01.041.

31. Lutenegger AJ (2012) Collapse Bsensitivity^ of midcontinent and lower Mississippi Valley loess. Geocongress 225:880-889, https://doi.org/10.1061/9780784412121.091.

32. Mohammady, M., Pourghasemi, H. R., Pradhan, B (2012) Landslide susceptibility mapping at Golestan Province, Iran: a comparison between frequency ratio, Dempster-Shafer, and weights-of-evidence models. Journal of Asian Earth Sciences, 61, 221-236, https://doi.org/10.1016/j.jseaes.2012.10.005.

33. Okhravi, R (2001) Characteristics and provenance of the loess deposits of the Gharatikan watershed in Northeast Iran. Global and Planetary Change, 28(1-4), 11-22, doi: 10.1016/s0921-8181(00)00061-8.

34. Pandey, V. K., Pourghasemi, H. R., \& Sharma, M. C (2018) Landslide susceptibility mapping using maximum entropy and support vector machine models along the Highway Corridor, Garhwal Himalaya. Geocarto International, 1-38, doi:10.1080/10106049.2018.1510038.

Page $11 / 24$ 
35. Penga, J., Sunc, P., Igwed, O., Lia, X (2017) Loess caves, a special kind of geo-hazard on loess plateau, northwestern China. Eng. Geol, 236, 1-4. This issue, doi: 1016/j.enggeo.2017.08.012.

36. Pourghasemi, H.R., Kariminejad, N., Gayen, A., Komac, M (2019) Statistical functions used for spatial modelling due to assessment of landslide distribution and landscape interaction factors in Iran. Geosci. Front, 1-13, https://doi.org/10.1016/j.gsf.2019. 11.005.

37. Pourghasemi, H. R., Yousefi, S., Kornejady, A., \& Cerdà, A (2017) Performance assessment of individual and ensemble data-mining techniques for gully erosion modeling. Science of The Total Environment, 609, 764775, doi:10.1016/j.scitotenv.2017.07.198.

38. Rezaiy, H., Lashkaripour, G.R., Ghafoori, M (2011) Engineering Geology Criteria for Evaluation and Classification of Loess in Golestan Province. Basic. Appl. Sci. Res., 1(12)2979-2986.

39. Richthofen, F.F. von (1877) China. Ergebnisse eigener reisen und darauf gegründeter Studien. Bd. 1, Einleittender theil Berlin, D. Reimer, 1-758.

40. Salehi, T., Shokrian, M., Modirrousta, A., Khodabandeh, M., Heidari, M (2015) Estimation of the collapse potential of loess soils in Golestan Province using neural networks and neuro-fuzzy systems. Arabian Journal of Geosciences, 8(11), 9557-9567, doi: 10.1007/s12517-015-1894-4.

-Smalley, I., Marković, S. B., \& Svirčev, Z (2011) Loess is [almost totally formed by] the accumulation of dust. Quaternary International, 240(1-2), 4-11, doi:10.1016/j.quaint.2010.07.011.

41. Wang, L., Shao, S., \& She, F (2019) A New Method for Evaluating Loess Collapsibility and Its Application. Engineering Geology, 105376, doi:10.1016/j.enggeo.2019.105376.

42. Soufi, M (2002) Characteristics and Causes of Gully Erosion in Iran. In: 12th ISCO Conference, Beijing, China.

43. Xie, W.-L., Li, P., Vanapalli, S. K., Wang, J.-D (2018) Prediction of the wetting-induced collapse behaviour using the soil-water characteristic curve. Journal of Asian Earth Sciences, 151, 259268, doi:10.1016/j.jseaes.2017.11.009.

44. Zare, M., Pourghasemi, H. R., Vafakhah, M., Pradhan, B (2013) Landslide susceptibility mapping at Vaz Watershed (Iran) using an artificial neural network model: a comparison between multilayer perceptron (MLP) and radial basic function (RBF) algorithms. Arabian Journal of Geosciences, 6(8), 2873-2888, https://doi.org/10.1007/s12517-012- 0610-x.

45. Zhang, Y., Hu1, Z., Xue, Z (2018) A new method of assessing the collapse sensitivity of loess. Bulletin of Engineering Geology and the Environment, https://doi.org/10.1007/s10064-018-1372-9.

\section{Tables}

Table 1

Physical and mechanical properties of Loess soil samples in the studied areas 


\begin{tabular}{|c|c|c|c|c|c|c|c|c|c|c|}
\hline $\begin{array}{l}\text { Zone } \\
\text { Number }\end{array}$ & location & $\begin{array}{l}\text { Sample } \\
\text { Number }\end{array}$ & Sand\% & Silt\% & Clay\% & $W \%$ & $S r \%$ & $n \%$ & $\mathrm{CaCO}_{3 \%}$ & $L L \%$ \\
\hline \multirow[t]{12}{*}{ Zone I } & \multirow{3}{*}{$\begin{array}{l}\text { Seyed } \\
\text { Miran }\end{array}$} & $S-M 1$ & 2.12 & 54.67 & 36.56 & 4.89 & 12.10 & 46.2 & 27.17 & 51.8 \\
\hline & & $S-M 2$ & 1.90 & 52.31 & 38.82 & 5.56 & 16.50 & 43.8 & 19.73 & 52.0 \\
\hline & & $S-M 3$ & 2.10 & 53.62 & 37.48 & 7.12 & 24.60 & 41.2 & 18.08 & 51.64 \\
\hline & \multirow[t]{3}{*}{ Saad Abad } & $S A 1$ & 2.80 & 55.43 & 34.34 & 5.12 & 13.50 & 45.4 & 25.5 & 50.4 \\
\hline & & $S A 2$ & 2.49 & 55.00 & 35.54 & 6.68 & 16.30 & 41.72 & 18.4 & 48.7 \\
\hline & & $S A 3$ & 1.85 & 53.50 & 38.18 & 8.43 & 22.47 & 40.05 & 16.36 & 49.1 \\
\hline & \multirow[t]{3}{*}{ Baraftan } & B1 & 6.35 & 65.81 & 26.61 & 9.16 & 17.60 & 47.8 & 31.34 & 26.81 \\
\hline & & $B 2$ & 5.89 & 64.72 & 28.03 & 11.30 & 33.53 & 46.3 & 35.4 & 36.74 \\
\hline & & B3 & 6.15 & 65.53 & 27.43 & 12.16 & 21.17 & 43.9 & 34.11 & 26.85 \\
\hline & \multirow[t]{3}{*}{ Agh Emam } & $A G-E 1$ & 1.11 & 78.25 & 20.67 & 12.60 & 41.90 & 42.5 & 18.24 & 34.6 \\
\hline & & $A G-E 2$ & 0.98 & 77.94 & 21.03 & 12.45 & 49.94 & 40.7 & 16.4 & 33.9 \\
\hline & & $A G-E 3$ & 1.16 & 78.48 & 20.42 & 13.48 & 55.45 & 36.3 & 22.91 & 34.8 \\
\hline \multirow[t]{10}{*}{ Zone II } & \multirow[t]{2}{*}{ Agh Abad } & $A G 1$ & 1.52 & 76.12 & 22.39 & 7.31 & 15.10 & 48.4 & 28.94 & 31.0 \\
\hline & & $A G 2$ & 0.85 & 77.30 & 21.72 & 6.61 & 14.26 & 51.8 & 36.65 & 30.7 \\
\hline & \multirow{2}{*}{$\begin{array}{l}\text { Gonbad- } \\
\text { Kalaleh }\end{array}$} & $G-K 1$ & 2.55 & 80.91 & 16.65 & 7.23 & 19.40 & 49.6 & 41.13 & 32.6 \\
\hline & & $G-K 2$ & 1.80 & 80.34 & 17.80 & 9.68 & 23.65 & 46.5 & 33.38 & 32.7 \\
\hline & \multirow[t]{3}{*}{ Feraghi } & $F 1$ & 13.2 & 27.30 & 27.35 & 7.81 & 9.31 & 39.45 & 20.4 & 29.5 \\
\hline & & $F 2$ & 7.14 & 28.93 & 28.96 & 6.30 & 7.27 & 38.4 & 21.2 & 24.3 \\
\hline & & F3 & 9.21 & 26.13 & 26.12 & 8.52 & 8.92 & 39.52 & 28.7 & 31.2 \\
\hline & \multirow[t]{3}{*}{ Cheshmehli } & $\mathrm{CH} 1$ & 12.70 & 64.15 & 23.28 & 5.24 & 6.60 & 44.4 & 24.1 & 22.1 \\
\hline & & $\mathrm{CH} 2$ & 13.22 & 68.62 & 17.31 & 7.16 & 7.15 & 40.2 & 26.2 & 22.4 \\
\hline & & $\mathrm{CH} 3$ & 15.10 & 68.35 & 15.81 & 8.86 & 7.85 & 40.33 & 30.1 & 19.85 \\
\hline \multirow[t]{8}{*}{ Zone III } & \multirow[t]{3}{*}{ Alagol } & $A / 1$ & 33.10 & 66.96 & 0.00 & 4.37 & 6.62 & 46.4 & 35.41 & 0.00 \\
\hline & & $A / 2$ & 32.40 & 67.62 & 0.00 & 3.90 & 7.30 & 50.8 & 23.37 & 0.00 \\
\hline & & $A / 3$ & 34.60 & 65.44 & 0.00 & 5.52 & 5.36 & 42.1 & 36.65 & 0.00 \\
\hline & \multirow[t]{3}{*}{ Tangli } & $T 1$ & 24.90 & 62.87 & 8.14 & 4.95 & 8.41 & 48.3 & 36.16 & 18.03 \\
\hline & & $T 2$ & 25.90 & 63.29 & 7.85 & 4.16 & 9.36 & 49.7 & 39.05 & 17.7 \\
\hline & & T3 & 26.34 & 60.24 & 9.54 & 5.63 & 11.85 & 47.2 & 32.33 & 18.3 \\
\hline & \multirow{2}{*}{$\begin{array}{l}\text { Hootan- } \\
\text { Korand }\end{array}$} & $H 1$ & 36.20 & 57.36 & 4.17 & 4.12 & 6.13 & 49.8 & 41.4 & 0.00 \\
\hline & & $\mathrm{H} 2$ & 35.13 & 59.12 & 4.38 & 3.38 & 5.50 & 51.3 & 33.2 & 0.00 \\
\hline
\end{tabular}




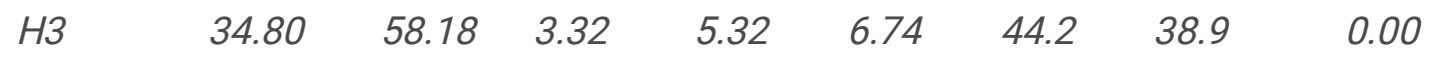

W: Water content, Sr: Degree of Saturation, n: Porosity, LL: Liquid limit.

\section{Table 2}

Comparison of the collapse coefficient, the time required for $90 \%$ soil settlement, and c stability time of triple Zones 


\begin{tabular}{|c|c|c|c|c|c|}
\hline Zone Number & location & Sample Number & Ic & T90\% (min) & Stability time (min) \\
\hline \multirow[t]{12}{*}{ Zone I } & \multirow[t]{3}{*}{ Seyed Miran } & $S-M 1$ & 1.44 & 91.5 & 6.15 \\
\hline & & $S-M 2$ & 10.31 & 83.2 & 5.25 \\
\hline & & $S-M 3$ & 1.78 & 88.5 & 3.58 \\
\hline & \multirow[t]{3}{*}{ Saad Abad } & $S A 1$ & 1.39 & 122.7 & 7.16 \\
\hline & & $S A 2$ & 9.82 & 116 & 5.25 \\
\hline & & $S A 3$ & 6.64 & 145 & 4.38 \\
\hline & \multirow[t]{3}{*}{ Baraftan } & $B 1$ & 2.22 & 68.5 & 7.15 \\
\hline & & $B 2$ & 1.36 & 70.6 & 6.55 \\
\hline & & $B 3$ & 6.94 & 81.2 & 7.37 \\
\hline & \multirow[t]{3}{*}{ Agh Emam } & $A G-E 1$ & 1.1 & 66.33 & 8.18 \\
\hline & & $A G-E 2$ & 0.96 & 70.1 & 5.46 \\
\hline & & $A G-E 3$ & 0.74 & 72.2 & 3.58 \\
\hline \multirow[t]{10}{*}{ Zone II } & \multirow[t]{2}{*}{ Agh Abad } & $A G 1$ & 14.95 & 76.3 & 3.25 \\
\hline & & $A G 2$ & 17.79 & 28.2 & 2.52 \\
\hline & \multirow[t]{2}{*}{ Gonbad-Kalaleh } & $G-K 1$ & 7.21 & 39.3 & 2.5 \\
\hline & & $G-K 2$ & 4.39 & 8.8 & 2.25 \\
\hline & \multirow[t]{3}{*}{ Feraghi } & $F 1$ & 15.2 & 4.6 & 2.38 \\
\hline & & $F 2$ & 18.1 & 4.8 & 2.48 \\
\hline & & F3 & 14.3 & 13.5 & 4.3 \\
\hline & \multirow[t]{3}{*}{ Cheshmehli } & $\mathrm{CH} 1$ & 19.1 & 3.5 & 2.25 \\
\hline & & $\mathrm{CH} 2$ & 21.3 & 6.2 & 3.18 \\
\hline & & $\mathrm{CH} 3$ & 19.2 & 4.7 & 2.55 \\
\hline \multirow[t]{9}{*}{ Zone III } & \multirow[t]{3}{*}{ Alagol } & $A / 1$ & 18.61 & 33.1 & 3.52 \\
\hline & & $A / 2$ & 20.2 & 54.4 & 4.36 \\
\hline & & $A / 3$ & 16.83 & 43.5 & 6.25 \\
\hline & \multirow[t]{3}{*}{ Tangli } & $T 1$ & 5.82 & 29.2 & 2.41 \\
\hline & & $T 2$ & 17.33 & 38.6 & 2.53 \\
\hline & & T3 & 4.66 & 53.5 & 8.15 \\
\hline & \multirow[t]{3}{*}{ Hootan-Korand } & $H 1$ & 24.8 & 14.2 & 4.12 \\
\hline & & $H 2$ & 26.8 & 51.5 & 6.25 \\
\hline & & H3 & 20.71 & 12.5 & 3.35 \\
\hline
\end{tabular}


$\mathrm{I}_{\mathrm{C}}$ : coefficient of collapse, $\mathrm{T}_{90 \%}$ : Collapse rate

\section{Table 3}

Grades of collapse sensitivity in loess (Zhang et al., 2018)

\begin{tabular}{|llll|}
\hline $\mathrm{T}(\mathrm{min})$ & $\mathrm{I}_{\mathrm{C}}(\%)$ & & \\
\cline { 2 - 4 } & $0.015<\mathrm{I}_{\mathrm{C}} \leq 0.03$ & $0.03<\mathrm{I}_{\mathrm{C}} \leq 0.07$ & $\mathrm{I}_{\mathrm{C}}>0.07$ \\
\hline $60 \mathrm{~T}$ & Slight & Slight & Moderate \\
\hline $15<\mathrm{T} \leq 60$ & Slight & Moderate & Moderate severe \\
\hline $5 \leq \mathrm{T} \leq 15$ & Moderate & Moderate severe & Severe \\
\hline $\mathrm{T}<5$ & Moderate severe & Severe & Severe \\
\hline
\end{tabular}

\section{Table 4}

Grades of collapse sensitivity of loess soils in Golestan Province 


\begin{tabular}{|c|c|c|c|}
\hline Zone Number & location & Sample Number & Is \\
\hline \multirow[t]{12}{*}{ Zone I } & \multirow[t]{3}{*}{ Seyed Miran } & $S-M 1$ & Slight \\
\hline & & $S-M 2$ & Moderate \\
\hline & & $S-M 3$ & Slight \\
\hline & \multirow[t]{3}{*}{ Saad Abad } & $S A 1$ & Slight \\
\hline & & $S A 2$ & Moderate \\
\hline & & $S A 3$ & Slight \\
\hline & \multirow[t]{3}{*}{ Baraftan } & $B 1$ & Slight \\
\hline & & $B 2$ & Slight \\
\hline & & B3 & Moderate \\
\hline & \multirow[t]{3}{*}{ Agh Emam } & $A G-E 1$ & Slight \\
\hline & & $A G-E 2$ & Slight \\
\hline & & $A G-E 3$ & Slight \\
\hline \multirow[t]{10}{*}{ Zone II } & \multirow[t]{2}{*}{ Agh Abad } & $A G 1$ & Moderate \\
\hline & & $A G 2$ & Moderately severe \\
\hline & \multirow[t]{2}{*}{ Gonbad-Kalaleh } & $G-K 1$ & Moderately severe \\
\hline & & $G-K 2$ & Moderately severe \\
\hline & \multirow[t]{3}{*}{ Feraghi } & $F 1$ & Sever \\
\hline & & $F 2$ & Sever \\
\hline & & F3 & Sever \\
\hline & \multirow[t]{3}{*}{ Cheshmehli } & $\mathrm{CH} 1$ & Sever \\
\hline & & $\mathrm{CH} 2$ & Sever \\
\hline & & $\mathrm{CH} 3$ & Sever \\
\hline \multirow[t]{9}{*}{ Zone III } & \multirow[t]{3}{*}{ Alagol } & $A / 1$ & Moderately severe \\
\hline & & $A / 2$ & Moderately severe \\
\hline & & $A / 3$ & Moderately severe \\
\hline & \multirow[t]{3}{*}{ Tangli } & $T 1$ & Moderate \\
\hline & & $T 2$ & Moderately severe \\
\hline & & T3 & Moderately severe \\
\hline & \multirow[t]{3}{*}{ Hootan-Korand } & $H 1$ & Sever \\
\hline & & $H 2$ & Moderately severe \\
\hline & & $H 3$ & Sever \\
\hline
\end{tabular}

Page 17/24 


\section{Figures}
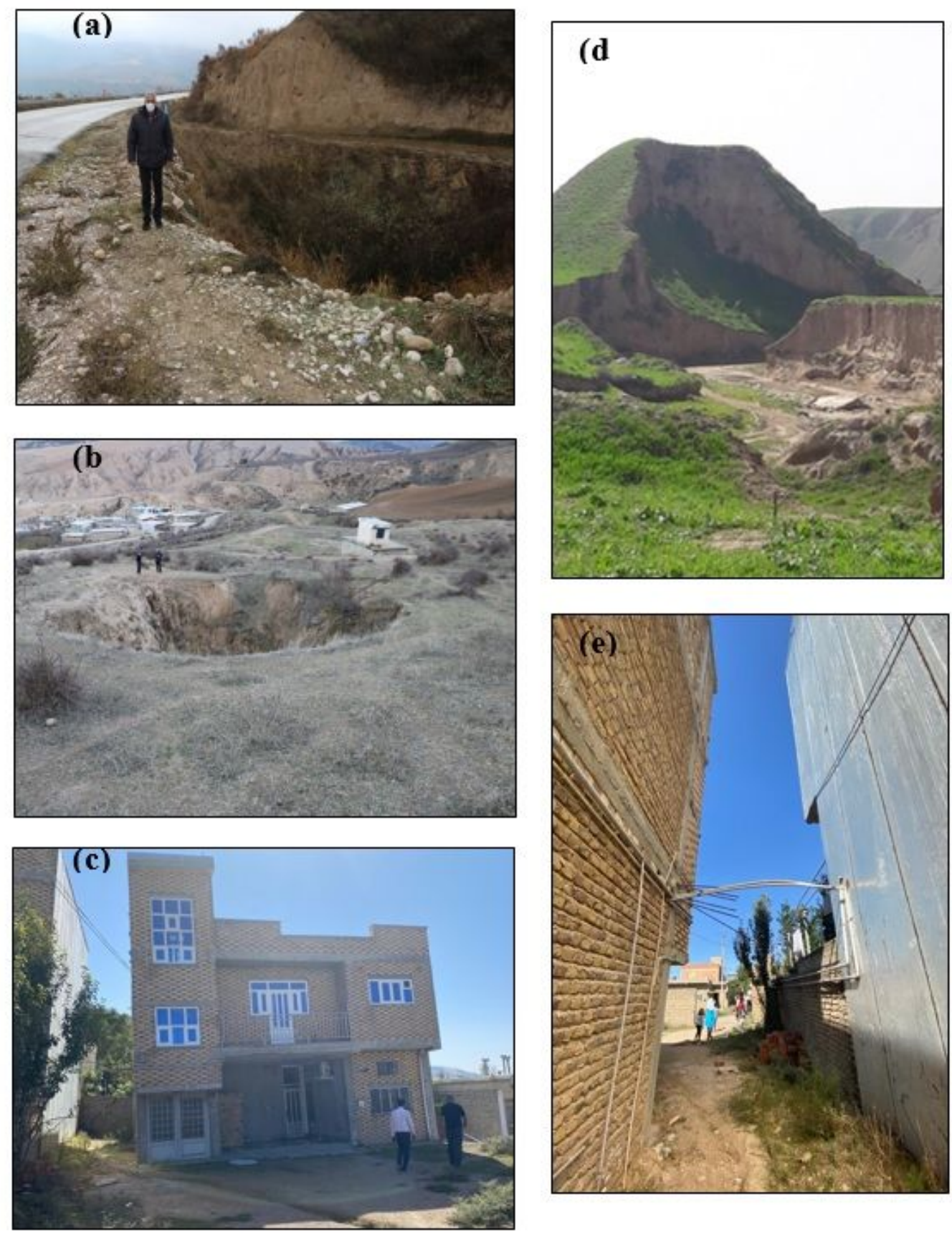

\section{Figure 1}

a) A loess sinkhole developed along the Kalaleh-Maraveh Tappe road b) A large pseudokarst sinkhole developed near the Cheshmehli village c) Differential settlement of residential building in Feraghi city due to collapse settlement d) Typical landslide developed on loess plateau in Golestan Province, and e) Bending of gas supply pipe of houses in Feraghi city due to loess collapse 


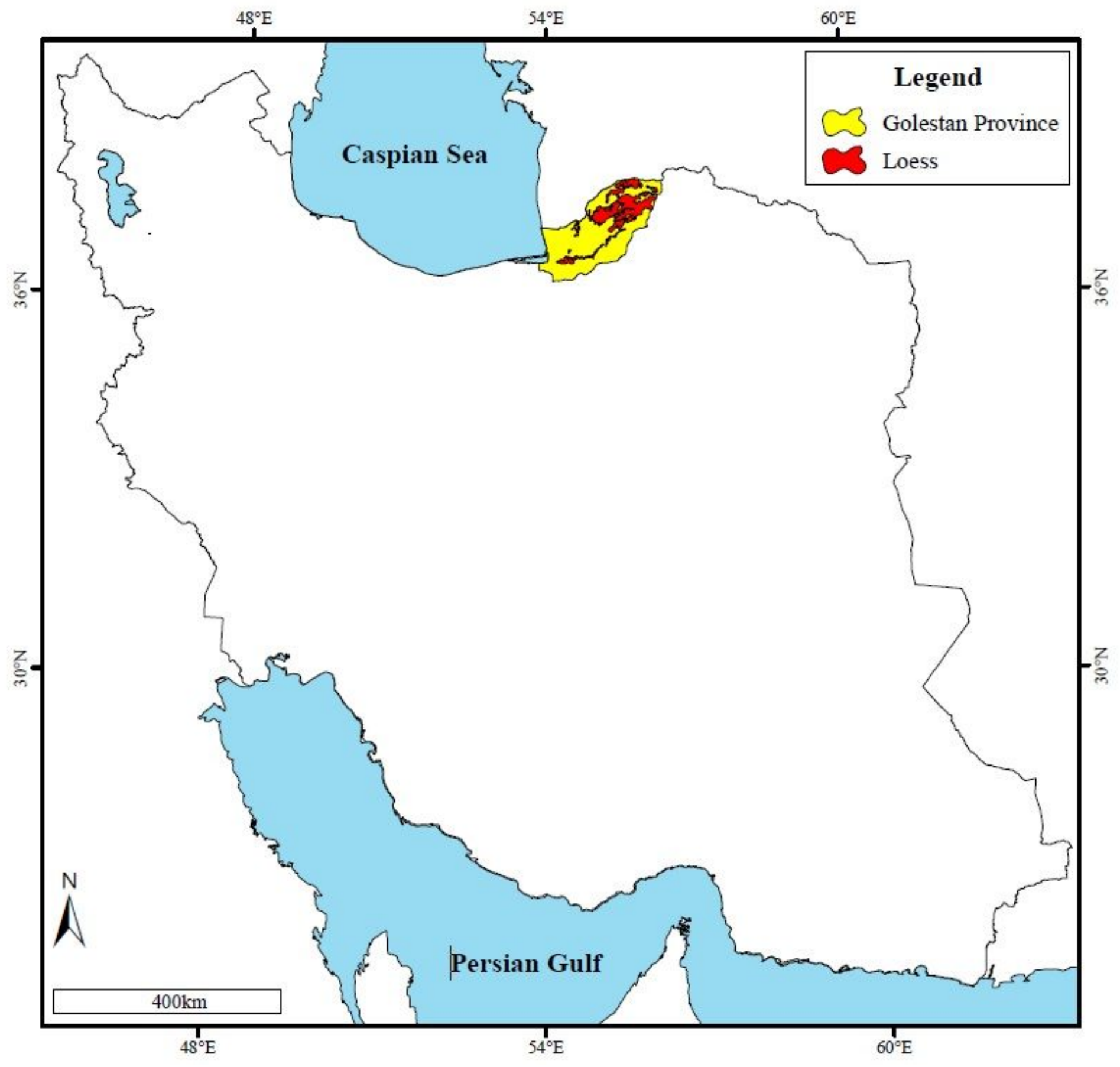

Figure 2

Location map of the study area 


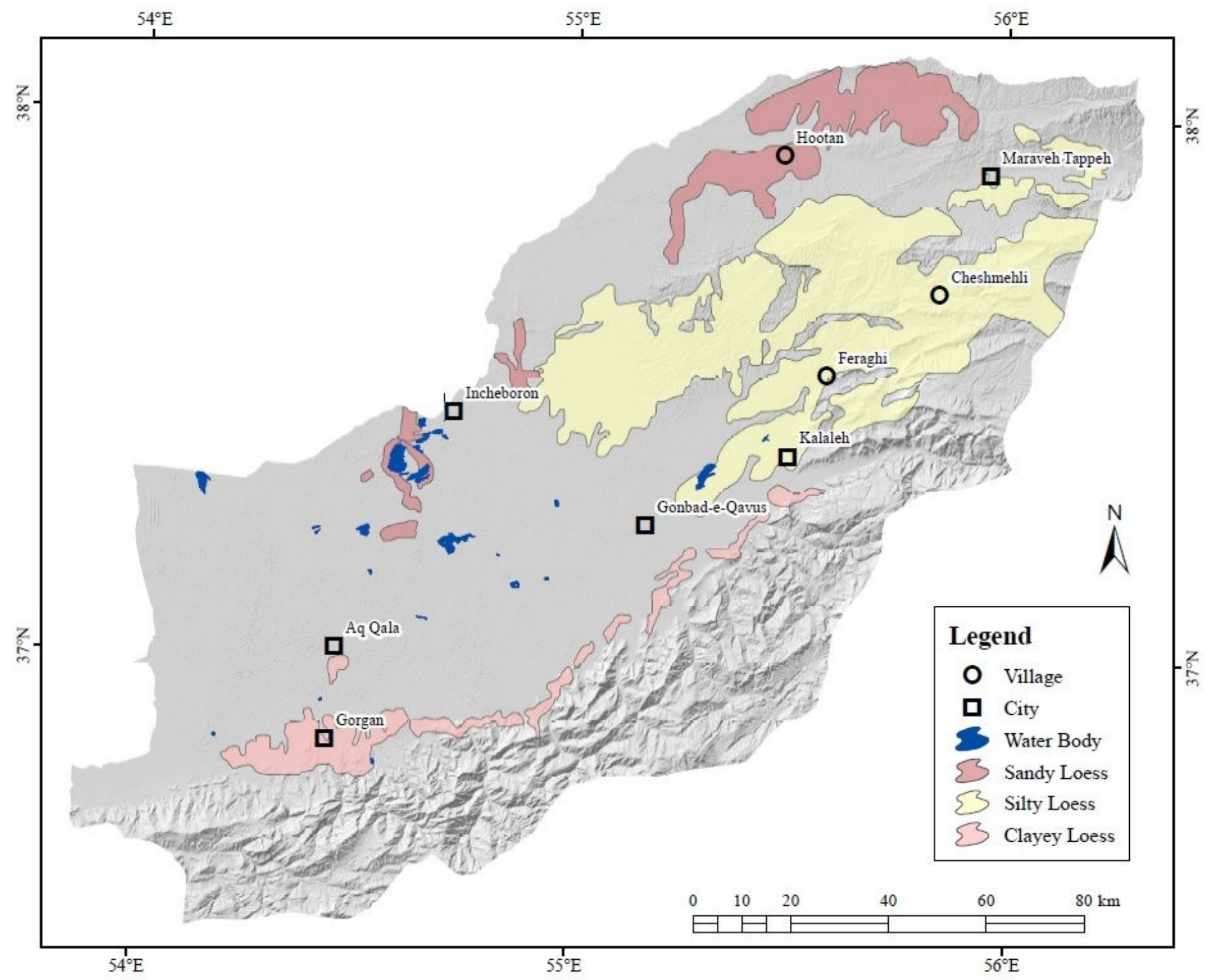

Figure 3

Distribution of loess plateau in Golestan Province 

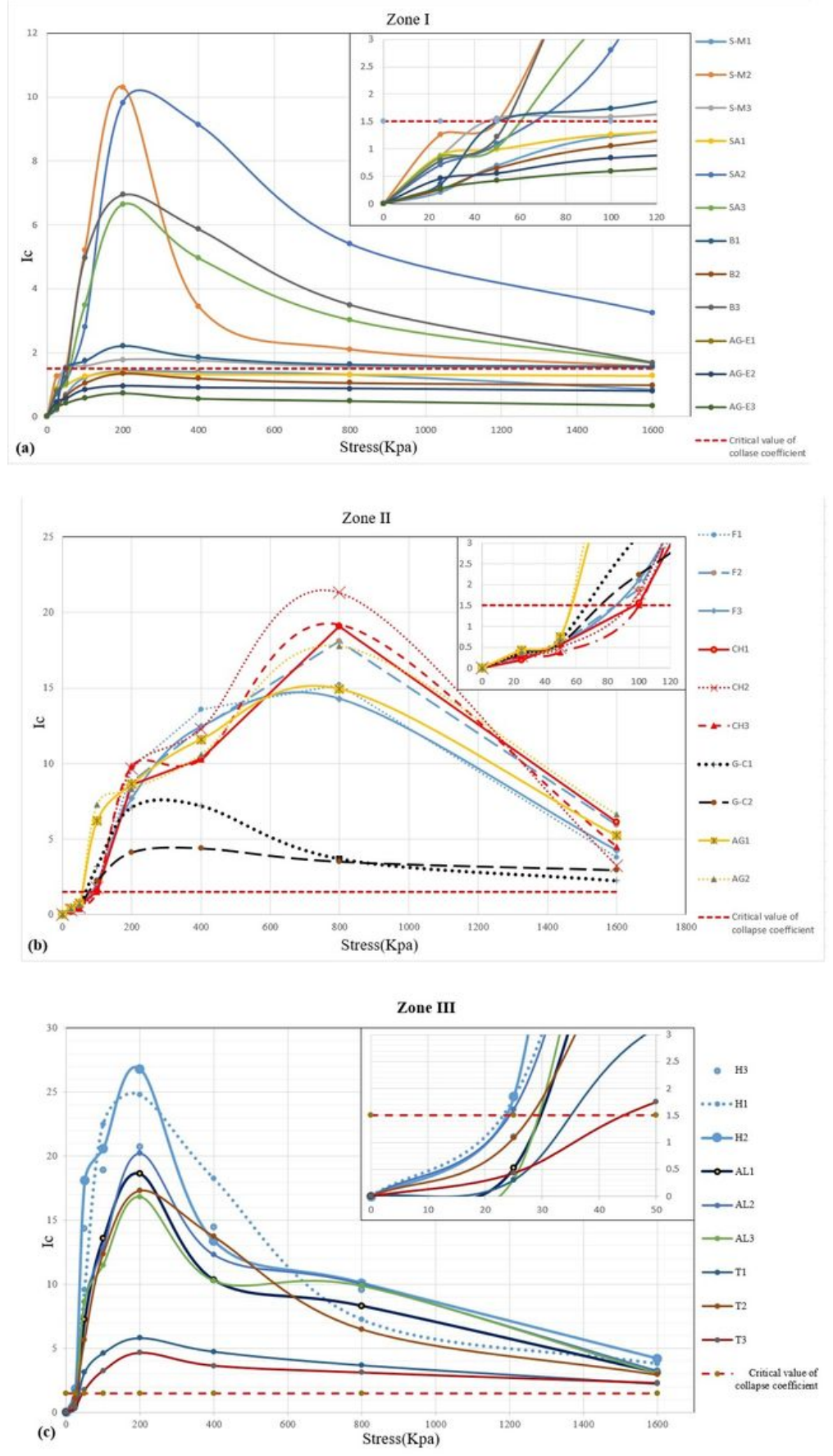

\section{Figure 4}

Variation of the Ic of soil samples in the triple Zones a) Zone I, b) Zone II, c) Zone III 


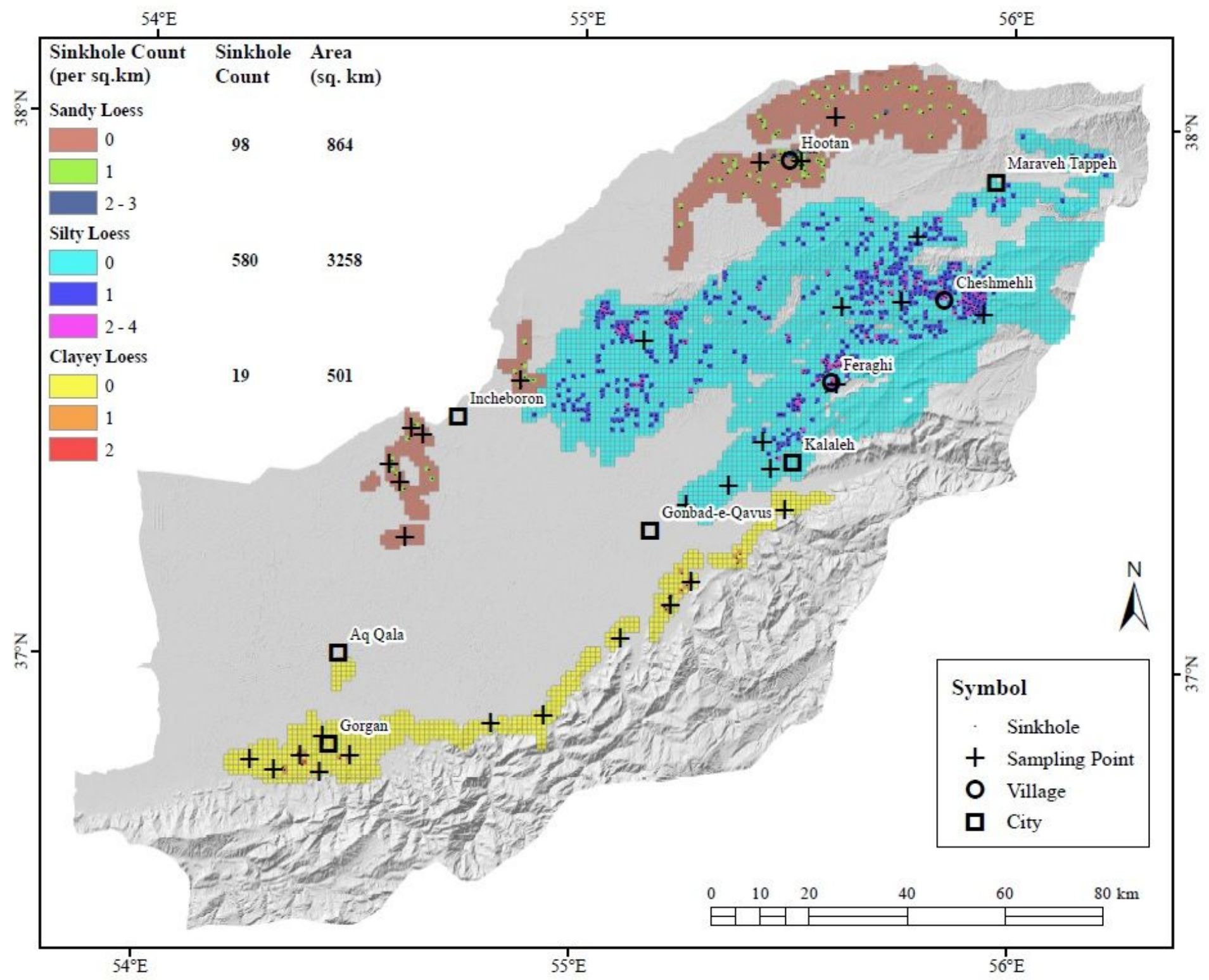

Figure 5

Spatial distribution of sinkholes $(n=697)$ in loess zones of Golestan Province, projected on a map 


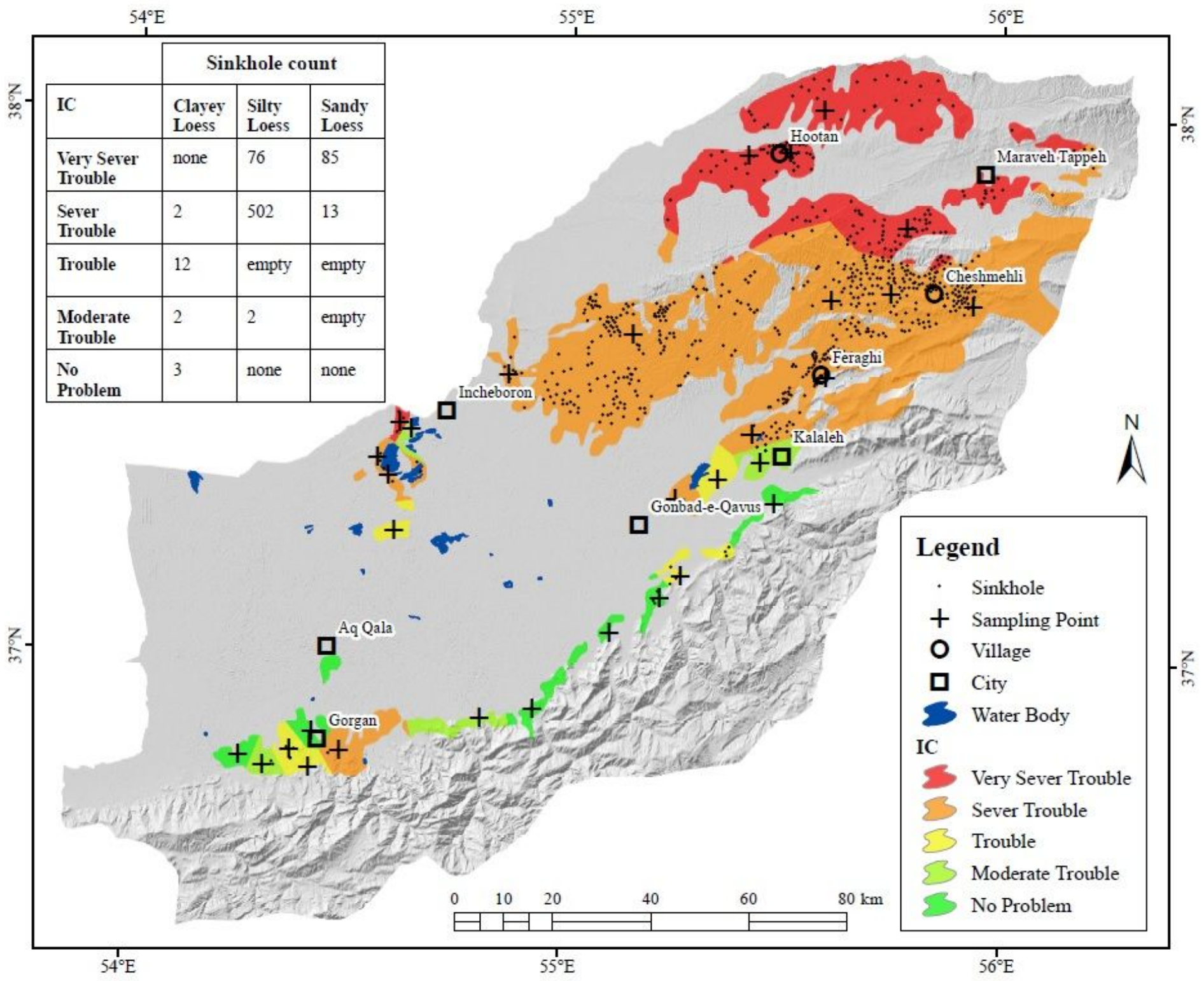

Figure 6

Relationship between spatial distribution of sinkholes and collapse coefficient 


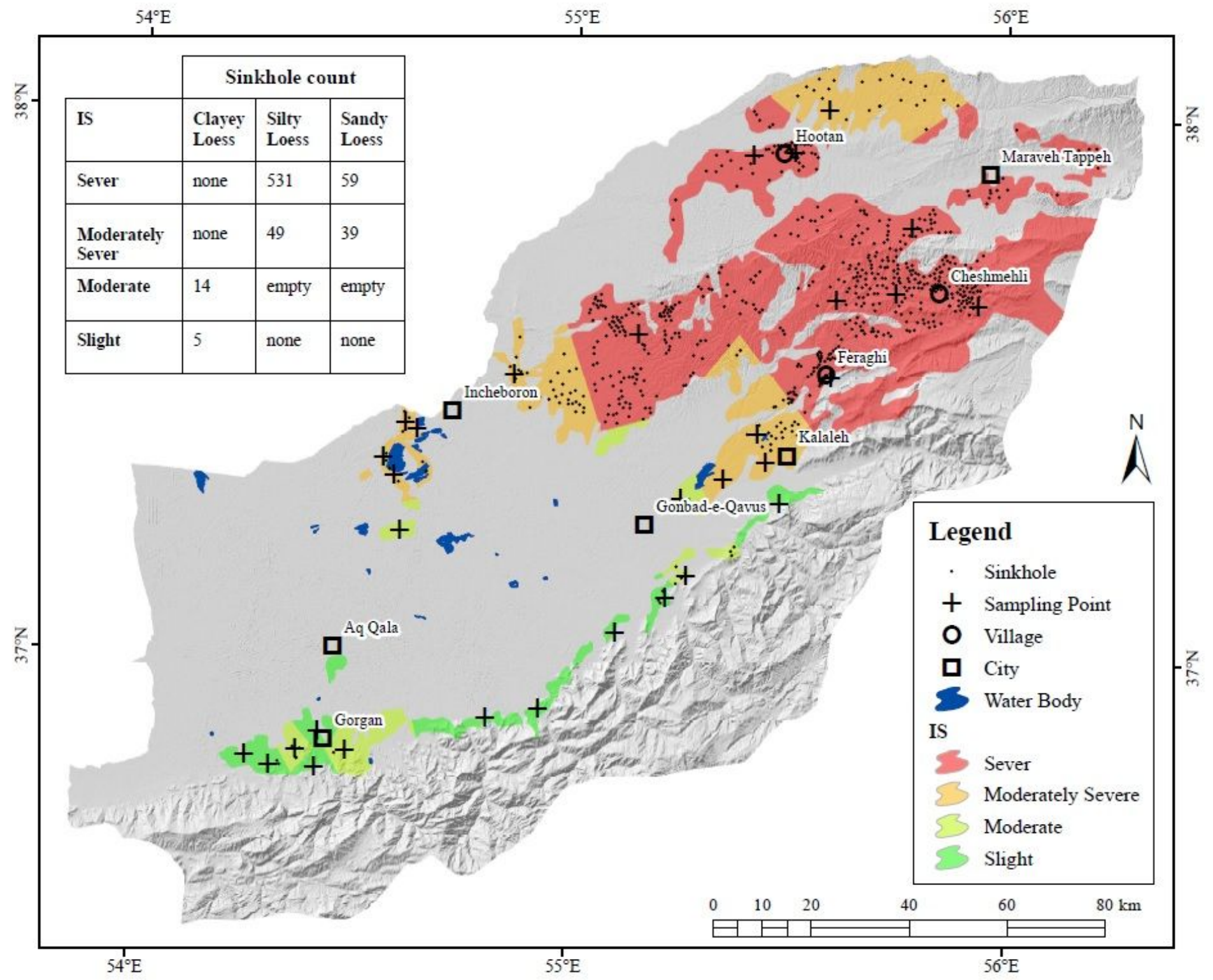

Figure 7

Relationship between spatial distribution of loess sinkholes and Sensitivity collapse 